\title{
Un medio marino del que estar orgullosos (por ahora)
}

José Templado'

Javier Pantoja ${ }^{2}$

Sumario: I. UN MEDIO MARINO PRIVILEGIADO. II. ALGUNAS NOCIONES SOBRE BIODIVERSIDAD MARINA. III. NUESTRA BIODIVERSIDAD MARINA. 1. La biodiversidad pelágica. A) Fitoplancton. B) Zooplancton. C) Necton. 2. La biodiversidad bentónica. 3. Praderas submarinas. 4. Los bosques de laminarias. 5. Las comunidades de Cystoseira. 6. Las bioconstrucciones calcáreas. 7. Los fondos coralígenos. 8. Fondos de corales blancos profundos. IV. BENEFICIOS QUE NOS REPORTA EL MEDIO MARINO. V. LAS AGRESIONES AL MEDIO MARINO. VI. MEDIDAS INTERNACIONALES DE CONSERVACIÓN DE LA BIODIVERSIDAD MARINA.

\section{UN MEDIO MARINO PRIVILEGIADO}

En el medio marino español confluyen una serie de características muy notorias desde diferentes puntos de vista, lo que le confiere gran singularidad e importancia. En lo referente a la geomorfología, los cerca de $8.000 \mathrm{~km}$ de litoral (incluyendo el de los archipiélagos canario y balear) nos ofrecen una extraordinaria variedad de tipos de costa (rías, marismas, lagunas litorales, extensas costas acantiladas, playas, conjuntos insulares de extensión muy variable, ... ). Por otro lado nuestra situación geográfica entre el océano Atlántico y el mar Mediterráneo (y entre el continente europeo y el africano) es privilegiada y propicia que en nuestras aguas incidan diferentes condiciones oceanográficas. Asimismo, desde el punto de vista biogeográfico hay que destacar que el sur de la península Ibérica es el punto de confluencia de tres provincias biogeográficas marinas distintas, cada una con características propias: la Lusitana, de carácter templadofrío, la Mauritana, con influencia subtropical, y la Mediterránea, con toda una serie de peculiaridades propias. Esta extraordinaria heterogeneidad geomorfológica, oceanográfica y biogeográfica, se traduce en una gran variedad de su medio marino, lo cual se refleja en la diversidad de su flora y su fauna. Todo lo anterior se traduce en que España

1 Museo Nacional de Ciencias Naturales. CSIC.

2 Ministerio de medio ambiente y medio rural y marino. 
atesora, con mucha diferencia, la mayor diversidad biológica marina en el ámbito europeo, un patrimonio extraordinariamente valioso que debemos conservar.

Las diferencias entre las regiones geográficas atlántica y mediterránea son muy notables, tanto en lo que se refiere a la oceanografía, como en lo que concierne a su flora y fauna. Las diferentes peculiaridades que se dan en cada uno de los diferentes sectores de nuestro litoral determinan que la composición de la diversidad biológica varíe según nos vayamos trasladando de uno a otro. En las costas del norte de España existen notables diferencias entre las aguas gallegas y las del golfo de Vizcaya. Mientras que la biota marina gallega tiene un carácter más frío y se asemeja más a la de las costas bretonas y del sur de las islas Británicas, la del litoral cántabro y vasco presenta una marcada "mediterranización" o carácter más cálido. En todo el litoral norte predomina la costa acantilada, sólo interrumpida por pequeñas playas, marismas y estuarios (las rías, en el caso de las costas gallegas). Por otro lado, el sector atlántico del golfo de Cádiz, aparte de su situación más sureña, se caracteriza por un litoral bajo con predominio de playas y una extensa plataforma continental, ocupada en su mayor parte por fondos fangosos. Esta zona, además de compartir muchas especies con las áreas próximas (Mediterráneo y costas atlánticas del norte de África), presenta algunos elementos faunísticos exclusivos.

Dentro de la biota que habita las aguas canarias, ya muy diferente y de tipo subtropical, se pueden apreciar también diferencias entre las islas orientales, bajo la influencia del afloramiento sahariano de agua fría y con gran abundancia de especies de interés pesquero, y las occidentales, con afinidades más tropicales.

En lo que se refiere al Mediterráneo, hay que resaltar en primer lugar que existe una marcada gradación decreciente de las cifras de diversidad de especies desde la cuenca occidental a la oriental de este mar. No debe olvidarse que la mayor parte de la biota mediterránea actual procede de sucesivas invasiones a partir del Atlántico. Así, por ejemplo, se estima que el $87 \%$ de la fauna mediterránea actual está presente en el Mediterráneo occidental, el $49 \%$ en el Adriático o el $47 \%$ en la cuenca oriental. Ello sitúa nuevamente a nuestro litoral mediterráneo en una situación privilegiada, lo cual se acentúa todavía más si tenemos en cuenta que en las costas mediterráneas españolas se observa, a su vez, toda una transición entre el litoral catalán, de afinidades más frías, y el sector más cálido, comprendido entre el cabo La Nao y el cabo de Gata. Aunque buena parte de las especies son comunes a todo nuestro litoral mediterráneo, otras muchas presentan una gradación y caracterizan los distintos sectores.

Por último, las costas mediterráneas del mar de Alborán presentan una notable influencia de la capa superficial de agua procedente del Atlántico. Toda esta zona constituye una encrucijada, donde pueden encontrarse especies atlánticas, tanto de aguas frías (de las costas europeas) como cálidas (de las costas africanas), junto a especies mediterráneas y diversos endemismos exclusivos de la zona. Hay que señalar que el cabo de Gata constituye una frontera muy marcada entre el sector más cá172 lido de nuestras costas mediterráneas y el área de influencia atlántica. 
Todo lo anterior señala a nuestro medio marino como un extraordinario reservorio de biodiversidad y fuente de recursos, no exento de amenazas, que es preciso conocer en profundidad, gestionar adecuadamente y conservarlo para generaciones futuras.

\section{ALGUNAS NOCIONES SOBRE BIODIVERSIDAD MARINA}

El medio marino presenta unas características muy diferentes a las del medio terrestre y, por tanto, su diversidad biológica es, asimismo, muy distinta, tanto en su composición como en su estructura y funcionamiento.

Es la mayor densidad del medio acuático frente al terrestre la que le confiere buena parte de sus atributos diferenciadores. En primer lugar, la mayor densidad supone una capacidad de absorción de energía notablemente más elevada, lo que determina que el medio marino sea mucho más estable. Su capacidad calorífica controla el clima a nivel global y estabiliza las temperaturas de la superficie. Asimismo, la densidad de este medio permite la vida en suspensión, lo que posibilita que distintas formas de vida ocupen todo el volumen de la gran masa de agua, aunque hay que precisar que la mayor parte la vida marina se concentra en las capas más superficiales (alrededor del 80\% de la biomasa habita por encima de los $1.000 \mathrm{~m}$ ). La existencia de vida en suspensión, así como de diversos tipos de partículas orgánicas y de nutrientes disueltos supone que el agua transporta en su seno una gran cantidad de alimento. Ello ha determinado que buena parte de los grupos o especies de animales marinos se hayan adaptado a la vida sésil (fija al sustrato) y a nutrirse simplemente por filtración. Por el contrario, en el medio terrestre todos los animales se ven obligados a desplazarse para obtener el alimento, mientras que sólo los vegetales pueden vivir fijos al sustrato. En el medio marino plantas y animales compiten por la ocupación del espacio y, de hecho, muchos paisajes o ecosistemas marinos están constituidos mayoritariamente por especies animales. El ejemplo más elocuente de ello lo constituyen los arrecifes de coral de mares tropicales.

Algunos de los grandes grupos que comprende el Reino Animal están constituidos exclusivamente por especies sésiles (esponjas, endoproctos, pogonóforos, foronídeos, briozoos, braquiópodos, ascidias). Otros, como los cnidarios, aunque cuentan también con especies de vida libre, son mayoritariamente sésiles y, asimismo, algunos grupos de animales originariamente móviles (como moluscos y anélidos), cuentan también con numerosísimas especies adaptadas a vivir fijas al sustrato y a alimentarse por filtración.

Por otro lado, aunque muchas de las especies marinas son bentónicas (viven asociadas a los fondos), buena parte de ellas poseen fases larvarias planctónicas, lo cual les confiere una gran capacidad de dispersión. Se estima que en torno al 70\% de las especies marinas tienen alguna fase larvaria planctónica. De la mayor o menor duración de dicha fase dependerá la capacidad de dispersión de las distintas espe- 
cies, pero se ha demostrado que en muchos casos las larvas planctónicas pueden retrasar considerablemente el momento de la metamorfosis en ausencia de los factores determinantes de la misma (normalmente la presencia de algún sustrato adecuado para el asentamiento), lo que confiere gran versatilidad a estas fases larvarias y aumenta la capacidad potencial de dispersión. Ello, unido a la ausencia de barreras geográficas, determina que las áreas de distribución de la mayor parte de las especies sean muy amplias.

La vida se originó en el mar, y de hecho, de los 35 filos o grandes grupos que se reconocen en la actualidad dentro del Reino Animal, sólo tres de ellos son exclusivos del medio terrestre, los unirrámeos (que incluyen a insectos y miriápodos), los pentastómidos y los onicóforos. Por el contrario, los restantes 32 filos tienen representación en el medio marino, siendo 16 exclusivos de este medio y otros 9 mayoritarios en él.

El medio marino se divide en dos grandes ecosistemas o dominios: el pelágico, constituido por la masa de agua que se extiende desde la superficie hasta el fondo, y el bentónico, formado por el fondo y por la capa de agua en inmediato contacto con el mismo. El conjunto de organismos que viven en el dominio pelágico se denomina pelagos, pero lo normal es que, a su vez, se distingan dentro de él el plancton, constituido por los organismos que son arrastrados pasivamente por las corrientes, y el necton, formado por aquellos cuya capacidad natatoria les permite desplazarse con independencia de éstas. Por otro lado, los organismos que viven en el dominio bentónico constituyen el bentos.

El dominio pelágico presenta una gran uniformidad y las especies que lo pueblan tienen áreas de distribución muy amplias, por lo que organismos del plancton o del necton no suelen servir para caracterizar zonas litorales concretas, y son las comunidades y especies bentónicas las que se utilizan para la descripción de las particularidades locales.

\section{NUESTRA BIODIVERSIDAD MARINA}

Un paso previo indispensable para una adecuada conservación y gestión de nuestra diversidad marina es conocerla lo más exhaustivamente posible. En este sentido, en las últimas décadas se han intensificado de modo muy notable los estudios en los campos de la botánica y zoología marinas en nuestro país, lo que ha conducido a que en el momento actual el nivel de conocimientos sobre nuestra diversidad marina pueda considerarse como aceptable, en lo que se refiere a aspectos básicos, como la taxonomía y la faunística. En aguas de nuestra plataforma continental se conocen hasta el momento unas 1.000 especies vegetales y más de 9.000 animales, con representantes de todos los filos presentes en el mar. Estas cifras corresponden sólo a es-

174 pecies pluricelulares, por lo que no incluyen grupos tan importantes como las diato- 
meas, con más de 500 especies conocidas en nuestras aguas, o los foraminíferos, con otras tantas.

Para hacernos una idea de lo que suponen estas cifras, se ofrece a continuación a grandes rasgos una comparación entre el número de especies pluricelulares marinas conocidas en aguas españolas y a nivel mundial:

TABLA 1

\begin{tabular}{|l|c|c|}
\hline \multicolumn{1}{|c|}{ Especies } & En el Mundo & En España \\
\hline Número total de especies & 200.000 & $10.300(5,1 \%)$ \\
\hline Vegetales & 6.600 & $1.050(15,9 \%)$ \\
\hline Animales & 193.000 & $9.250(4,8 \%)$ \\
\hline Vertebrados & 15.000 & $1.180(7,8 \%)$ \\
\hline Invertebrados & 178.000 & $8.070(4,5 \%)$ \\
\hline
\end{tabular}

En la tabla 2 se ofrecen los datos numéricos detallados por grupos a nivel mundial, europeo, mediterráneo y español, especificando también los datos correspondientes a las aguas canarias. De las 9.250 especies animales presentes en el medio marino español, unas 1.100 son planctónicas, unas 250 nectónicas (cetáceos, tortugas, algunos peces, buena parte de los cefalópodos y unos pocos crustáceos) y unas 7.900 bentónicas (cerca del 80\%). En cuanto a los grupos animales que cuentan con mayor representación en lo referente al número de especies conocidas, son los siguientes (en negrita se indican los grupos que están formados exclusivamente por especies sésiles):

\begin{tabular}{|l|c|}
\hline \multicolumn{1}{|c|}{ Especies } & Número \\
\hline Crustáceos & 2.500 \\
\hline Moluscos & 2.250 \\
\hline Peces & 1.130 \\
\hline Anélidos & 1.000 \\
\hline Cnidarios & 650 \\
\hline Esponjas & 550 \\
\hline Ascidias & 350 \\
\hline Briozoos & $\mathbf{2 8 0}$ \\
\hline Equinodermos & 275 \\
\hline
\end{tabular}

Cabe destacar, también, que desde 1975 se han descrito más de 400 especies nuevas para la ciencia de animales marinos en nuestras aguas (más de 170 moluscos, 
más de 65 de poliquetos, cerca de 50 de crustáceos, unas 35 de esponjas, cerca de 20 de cnidarios, otras tantas de briozoos y de ascidias, y ya en menor número, de nemertinos, gnatostomúlidos, tardígrados, endoproctos, equinodermos o peces).

A pesar de este buen nivel de conocimientos, es preciso señalar que todavía quedan importantes lagunas por cubrir. Existen algunos grupos importantes muy poco estudiados hasta ahora, como turbelarios, nematodos o algunos grupos de la fauna intersticial. Por otro lado, hay que mencionar que se desconoce la biología de buena parte de las especies, sobre todo dentro de los invertebrados.

Otra importante laguna, muy notoria, es la referida al conocimiento de la fauna de profundidad. La dificultad, por un lado, y la carestía de los medios que se requieren para ello, han determinado que sean muy escasos los estudios dedicados a la fauna batial que puebla el talud continental de nuestra plataforma, así como de las áreas profundas contiguas, los cañones submarinos o los denominados "seamounts" (elevaciones submarinas). Sin embargo en estos últimos años ha comenzado a darse un impulso al estudio de la biodiversidad de nuestros fondos profundos. Como ejemplo pueden citarse las intensas investigaciones que se vienen desarrollando en el denominado "banco de El Cachucho", situado frente a las costas asturianas (primera área marina de altamar protegida por el Estado Español), o en algunos cañones submarinos próximos a las costas catalanas. En la actualidad ha comenzado a desarrollarse un ambicioso proyecto financiado con fondos LIFE+ y con una duración de cinco años para la identificación y estudio de diez zonas de altamar que puedan ser designadas como lugares de la Red Natura 2000 (proyecto INDEMARES), incluyendo sus fondos profundos. Dicho proyecto está coordinado por la Fundación Biodiversidad del Ministerio de Medio Ambiente, y Medio Rural y Marino, con participación de distintas instituciones y ONGs.

\section{La biodiversidad pelágica}

Como ya se ha dicho, la distribución geográfica de los organismos pelágicos es, por lo general, muy amplia; tanto es así, que muchas de las especies son cosmopolitas, es decir, pueden encontrarse en cualquiera de los océanos. Por ello, los criterios para incluir en un catálogo nacional a las especies pelágicas son complejos. A continuación se comentan brevemente los principales componentes del medio pelágico.

\section{A) Fitoplancton}

Estos organismos microscópicos autótrofos que viven en el seno del agua tienen un papel crucial en la economía de los mares, ya que son los encargados de trasformar la energía solar en materia viva. Se conocen alrededor de 4.500 especies en el océano global, de la cuales un buen número son cosmopolitas. En nuestras aguas

176 atlánticas se han encontrado más de 1.000 y en el Mediterráneo alrededor de 1.400, 
muchas de ellas comunes en ambas regiones, por lo que contamos con entre el 25 y el $35 \%$ de todas las especies conocidas. Uno de los componentes mayoritario del fitoplancton son las diatomeas, con unas 500 especies en nuestras aguas.

\section{B) Zooplancton}

Es el nombre que recibe una compleja comunidad formada por animales en un rango de tallas muy variable. Dominan la biomasa del zooplancton los crustáceos, especialmente los copépodos, de los que en el ambiente pelágico se han descrito alrededor de 2.500 especies a nivel global. En aguas españolas se localizan al menos 700 de ellas y, en general, siempre son el grupo dominante en cualquier momento y época del año. Estos pequeños animales se alimentan sobre todo de diatomeas y, a su vez, constituyen el eslabón básico de las cadenas tróficas en el océano abierto, pues son el alimento fundamental de peces planctófagos, como boquerones, sardinas o arenques, y de las fases juveniles de otras muchas especies.

Los eufausiáceos, parecidos a pequeñas gambas, son el otro grupo de crustáceos planctónicos de gran importancia por su biomasa, ya que a pesar de no llegar al centenar de especies a nivel global, algunas de ellas pueden formar grandes concentraciones (el denominado "krill”), que son buscadas ávidamente por muchos animales planctófagos, entre ellos las ballenas. Otros grupos, como ostrácodos, anfípodos, cladóceros, misidáceos, sifonóforos, quetognatos, medusas, larvas de invertebrados y de peces, pueden ser temporalmente importantes en el plancton. En este sentido cabe señalar que, como se ha dicho, aproximadamente el $70 \%$ de las especies bentónicas presentan alguna fase larvaria planctónica, por lo que son habitantes temporales de la columna de agua. Atendiendo a ello, se denomina "holoplancton" al conjunto de especies que forman parte del plancton toda su vida, mientras que el "meroplancton" designa a aquellas que sólo lo hacen de forma temporal. Esto nos sirve de ejemplo para resaltar que en mares y océanos no hay compartimentos estancos y que existe una gran interconexión entre todos los ambientes y procesos.

\section{C) Necton}

Está formado por los animales nadadores del sistema pelágico, fundamentalmente vertebrados (peces, cetáceos y reptiles marinos), mientras que los invertebrados sólo están representados por el grupo de los cefalópodos y unos pocos crustáceos. Entre los peces, sólo 86 de las 566 especies marinas de nuestras aguas son pelágicas (un 15\%). Un buen número de ellos tienen gran importancia comercial, como los del orden clupeiformes: sardinas y anchoas, y el de los perciformes, entre cuyos representantes cabe mencionar lubinas, jureles, llampugas, palometas, besugos, listados, bonitos, atún rojo, atún blanco o pez espada. Al grupo de peces pelágicos pertenecen también tiburones, como marrajos, tintoreras y jaquetones. 
El grupo de los cetáceos, quizás el que despierta mayor atención y preocupaciones a nivel social por su conservación, cuenta en la actualidad con un centenar largo de especies en todo el mundo, de las que unas 35 pueden encontrarse en nuestras aguas. Ballenas, como la franca o de los vascos (Eubalaena glacialis), ahora avistada de forma excepcional, rorcuales como el común (Balaenoptera physalus ), cachalotes (Physeter macrocephalus) y varias especies de delfines (común, mular, listado, etc) tuvieron antiguamente mucha mayor abundancia que en la actualidad.

Por otro lado, los reptiles marinos son muy escasos y no superan la media docena de especies, de las que pueden encontrarse en nuestras aguas las tortugas boba, verde y laúd.

Por último, en aguas españolas se encuentran unas 80 especies de cefalópodos pelágicos, de las cuales algunas presentan gran interés pesquero, como potas y calamares.

\section{La biodiversidad bentónica}

En el medio marino, por lo general, los cambios son más acusados en el eje vertical que en el horizontal, ya que diversos factores abióticos como la temperatura, la luz, la presión, la densidad y el contenido en oxígeno o nutrientes, entre otros, varían con la profundidad. En el dominio bentónico, las variaciones en el eje vertical pueden ir acompañadas por una gran heterogeneidad en el plano horizontal, originada por cambios en la topografía y naturaleza del sustrato, por variaciones locales de los factores abióticos, o incluso por factores bióticos debidos a la actividad de los organismos. Esta heterogeneidad, tanto vertical como horizontal, determina una mayor biodiversidad de las comunidades bentónicas frente a la que presenta el dominio pelágico. Se estima que más del $80 \%$ de las especies marinas son bentónicas, al menos en su fase adulta. Sin embargo, es preciso indicar que el dominio bentónico presenta una gran dependencia funcional con respecto al plancton, ya que es muy deficitario en producción primaria.

Debido a la variación de los factores abióticos con el eje batimétrico, las comunidades bentónicas suelen presentar una distribución en bandas u horizontes, al menos en los niveles más superficiales, fenómeno conocido como "zonación". En función de ello, las comunidades bentónicas suelen agruparse una serie de franjas o zonas, denominadas usualmente "pisos", que de la costa a mar adentro van desde el supralitoral hasta el abisal, pasando por el mediolitoral, infralitoral, circalitoral y batial.

Hay que indicar que la zonación en el Atlántico y el Mediterráneo presenta diferencias que son suficientes para que los expertos den un tratamiento distinto a ambos. Aparte de esta zonación vertical, el principal factor determinante de la composi-

178 ción de las comunidades bentónicas es la naturaleza del sustrato: dura o blanda (es 
decir rocosa o sedimentaria). Son las comunidades asociadas a los sustratos duros las más heterogéneas y complejas, mientras que las que habitan los fondos sedimentarios suelen ser más homogéneas y con una diversidad de especies mucho menor. En estas últimas, factores como la granulometría y el contenido en materia orgánica juegan un papel muy importante. Además de las especies que viven sobre los sedimentos o enterradas en los mismos, cabe mencionar en este tipo de fondos la denominada fauna intersticial. Se trata de aquellos animales adaptados a vivir entre los granos del sedimento y que, por tanto, tienen un tamaño muy pequeño (inferior a $1 \mathrm{~mm}$ ). Hay que resaltar que de los 35 filos animales, 20 de ellos tienen algún representante intersticial y 5 (Gastrotricos, Quinorrincos, Loricíferos, Tardígrados y Gnatostomúlidos) son exclusivos de este medio. Otros grupos muy bien representados son los Crustáceos (Mistacocáridos, Copépodos Harpacticoides y Ostrácodos), Rotíferos, Nematodos (los más abundantes), Turbelarios y Poliquetos. Asimismo, algunos representantes de grupos como los Hidrozoos, Nemertinos, Endoproctos, Moluscos (Gasterópodos y Aplacóforos), Priapúlidos, Sipuncúlidos, Oligoquetos, Braquiópodos, Holoturoideos y Tunicados se han adaptado a la vida entre los granos del sedimento. Por tanto, la fauna intersticial contribuye a aumentar de forma muy notable las cifras de biodiversidad en un medio aparentemente pobre en especies.

No es posible hacer una descripción pormenorizada de todos los hábitats y comunidades bentónicas presentes en nuestras costas, por lo que a continuación se mencionan a modo de ejemplo sólo algunos de ellas, ya sea por su singularidad, interés o, simplemente, por ser las que mayor diversidad de especies reúnen.

\section{Praderas submarinas}

La vegetación marina está constituida mayoritariamente por algas, aunque un reducido número de especies de fanerógamas o plantas con flores (unas 60 en todos los océanos) se han adaptado de forma secundaria a la vida en el medio marino. Las fanerógamas ocupan amplias extensiones de los fondos someros y constituyen en los mares templados y cálidos uno de los ecosistemas litorales más importantes y característicos, las denominadas "praderas submarinas", que desempeñan un importante papel en la biología y dinámica costeras.

Casi siempre se instalan sobre sustratos sedimentarios, muy inestables, por lo que el entramado de rizomas de estas plantas contribuye a consolidar y estabilizar los sedimentos, a la vez que los enriquecen en materia orgánica. Las hojas actúan como un filtro para las partículas en suspensión, y favorecen su deposición, por lo que contribuyen a aumentar la claridad del agua. Además, las praderas de aguas someras atenúan la erosión costera. Asimismo, estas formaciones vegetales constituyen la principal fuente de producción primaria del sistema litoral, exportando oxígeno y materia orgánica al conjunto del sistema costero. Por último, las praderas de fanerógamas marinas constituyen el hábitat de muy numerosas especies, tanto vegetales como animales. Además de las especies que viven de forma habitual, otras muchas 
realizan sus puestas o desarrollan las fases juveniles en estas praderas. También es frecuente que muchos depredadores de aguas más profundas se desplacen durante la noche a estos lugares en busca de alimento. Todo ello determina un papel fundamental de estas formaciones vegetales en el conjunto de las cadenas tróficas del sistema litoral.

En las costas europeas existen cuatro especies de fanerógamas marinas, todas ellas presentes en el litoral español. Se trata de Zostera marina, Z. noltii, Cymodocea nodosa y Posidonia oceanica. La primera de ellas se extiende por las costas atlánticas y del mar de Alborán, mientras que la última, $P$. oceanica, es endémica del Mediterráneo. Las otras dos especies se encuentran tanto en las costas atlánticas como en las mediterráneas y son las únicas que llegan a las islas Canarias.

En las costas mediterráneas las praderas de Posidonia oceanica constituyen uno de los ecosistemas más emblemáticos, característico y que mayor biodiversidad alberga. Por ello estas praderas han sido incluidas por la Directiva Europea Hábitats como "hábitat de interés prioritario", al tiempo que como especie figura en el Anexo Il del Convenio de Barcelona para la protección del Mediterráneo.

\section{Los bosques de laminarias}

Las laminarias son algas feofíceas (pardas) de gran porte que se encuentran repartidas por los mares fríos y templados. Cubren amplias extensiones y dan lugar a lo que se denomina coloquialmente "bosques de laminarias", por presentar un cierto paralelismo con los bosques terrestres. En las costas europeas existen nueve especies de laminariales, de las que siete de ellas se encuentran en las costas españolas (de los géneros Laminaria, Saccorhiza y Phyllariopsis). Salvo Laminaria rodriguezii, que es endémica del Mediterráneo, las restantes especies son atlánticas, aunque algunas de ellas pueden extenderse por algunas zonas del Mediterráneo occidental. En concreto, Laminaria ochroleuca y Saccorhiza polyschides, que son más propias de aguas templadas y se extienden hasta Marruecos, forman espectaculares bosques en la zona del estrecho de Gibraltar y en los fondos que circundan la isla de Alborán, donde ocupan grandes extensiones entre 25 y $60 \mathrm{~m}$ de profundidad. Estas algas alcanzan aquí una gran talla, superando muchas veces los $4 \mathrm{~m}$ de altura, y la densidad de frondes es también muy elevada. Estos bosques albergan una comunidad extraordinariamente rica en especies.

\section{Las comunidades de Cystoseira}

Una buena parte de las comunidades algales mediterráneas se caracterizan por el desarrollo de diversas especies de algas pardas pertenecientes al género Cystosei$r a$. Dicho género presenta unas 50 especies en todo el mundo, de las que cerca de 30

180 están presentes en el Mediterráneo y unas 20 se encuentran en nuestras costas. Es- 
tas especies son muy sensibles a diversos factores ambientales, como luz, hidrodinamismo, o calidad del agua, y muchas de ellas constituyen los elementos dominantes de determinadas comunidades bentónicas bajo condiciones muy concretas. Todo ello las convierte en excelentes "indicadores ecológicos", siendo especialmente sensibles a la contaminación. Las especies de Cystoseira se caracterizan por su tamaño, relativamente grande, y por presentar talos más o menos robustos y profusamente ramificados.

Cabe destacar las comunidades superficiales de estas algas, que forman un denso y bien delimitado cinturón justo por debajo del nivel del mar, sobre sustrato rocoso en zonas moderadamente batidas. Se trata de la comunidad de Cystoseira mediterranea, en las costas catalanas, de C. amentacea, en el Levante español, $C$. tamariscifolia, en el mar de Alborán y estrecho de Gibraltar, y C. abies-marina, en Canarias. Se trata de cuatro especies vicarias cuya diferenciación morfológica es muy problemática y sólo posible para los especialistas, por lo que su distribución geográfica exacta no puede precisarse con exactitud. Dichas especies son excelentes indicadoras de aguas limpias, bien oxigenadas y exentas de contaminación y figuran en el Anexo II del Convenio de Barcelona ("especies en peligro o amenazadas" en el Mediterráneo).

Otras especies de este género pueden caracterizar también comunidades algales profundas, como C. spinosa, en el infralitoral inferior, o C. zosteroides, en el circalitoral superior, en zonas de aguas muy claras y sometidas a fuertes corrientes unidireccionales. Ambas especies son endémicas del Mediterráneo. La turbidez creciente de las aguas de este mar, junto a otros factores, está provocando la desaparición de estas comunidades algales profundas en muchas zonas, por lo que ambas especies han sido incluidas también en el Anexo II del Convenio de Barcelona. En nuestras costas están todavía bien desarrolladas en aguas de las Baleares y de las Columbretes.

En las costas atlánticas, aunque también están presentes algunas especies de este género, son especies de otros géneros las que dominan la franja litoral, como Pelvetia, Fucus, Himantalia, Bifurcaria, Chondrus, Gigartina, Gellidium y otros.

\section{Las bioconstrucciones calcáreas}

Muchas especies marinas, vegetales y animales, son capaces de generar un esqueleto calcáreo. En algunos casos estas especies crecen formando agregados más o menos densos y sus esqueletos pueden perdurar largos periodos de tiempo después de muertas. Ello puede dar lugar a la formación de estructuras más o menos duras y de diferentes formas y tamaños, en las cuales sólo las partes más superficiales permanecen vivas. Tales estructuras suelen denominarse "bioconstrucciones" o "bio-concrecionamientos", siendo los arrecifes de coral de los mares tropicales el ejemplo más conocido y representativo. 
En el Mediterráneo, a pesar de las altas temperaturas que se alcanzan en verano y de presentar muy numerosos elementos de tipo subtropical, no existen en la actualidad arrecifes de coral, pero sí toda otra serie de bioconstrucciones de diferentes tipos que, por lo general, pasan inadvertidas. Entre los principales organismos formadores de estructuras calcáreas se encuentran numerosas algas rodofíceas incrustantes, briozoos, moluscos, poliquetos serpúlidos y madreporarios. Estas estructuras de origen orgánico contribuyen a aumentar la complejidad estructural de los ambientes marinos y constituyen el hábitat para muchas otras especies. A continuación se presentan algunos ejemplos relevantes de bioconstrucciones presentes en nuestras costas:

- El madreporario Cladocora caespitosa. Se trata del coral cuyas colonias alcanzan mayor diámetro en el Mediterráneo y uno de los pocos corales coloniales que posee zooxantelas simbiontes y que, por tanto, vive en ambientes someros bien iluminados. Pertenece a la familia Faviidae, que es una de las más importantes en los arrecifes de coral. Dado que esta especie reúne las dos principales características de los corales hermatípicos (presencia de zooxantelas y la capacidad de formar arrecifes), puede ser clasificada como tal. Lo más frecuente es que presente morfologías almohadilladas o semiesféricas, en algunos lugares de hasta $1 \mathrm{~m}$ de diámetro. En el Mediterráneo los verdaderos arrecifes de coral desaparecieron al final del Messiniense (hace unos 5 m.a.), pero con posterioridad Cladocora caespitosa, especie endémica de este mar, llegó a formar en épocas relativamente recientes auténticos arrecifes en algunas zonas, como los del Plioceno Superior (hace unos 2 m.a.) en la zona del Cabo de Gata, o los que existieron hasta épocas históricas en el archipiélago balear. En la actualidad este madreporario parece estar en regresión, aunque todavía está presente en buena parte del Mediterráneo. En las costas españolas es frecuente en el litoral levantino y, especialmente, en las islas Baleares y en las Columbretes, donde todavía quedan pequeños bancos de coral (o agregaciones de colonias) de esta especie.

- Las cornisas mediolitorales. En el Mediterráneo, mar sin mareas, es frecuente que se formen cornisas o rebordes de algas calcáreas sobre las rocas, en torno al nivel medio del agua (piso mediolitoral), conocidos con el nombre de "trottoirs" en la literatura francesa. La más extendida de estas formaciones mesolitorales es la cornisa formada por los talos calcificados de la rodofícea Lithophyllum byssoides. Crece a modo de reborde, justo por encima del nivel medio del mar, en costas acantiladas expuestas al oleaje. Presenta un desarrollo muy variable según las zonas, pero puede alcanzar gran espesor y una amplitud de más de un metro, en algunos puntos. En las costas españolas alcanzan su máximo desarrollo en la Costa Brava, pero también están presentes en el litoral de la Comunidad Valenciana y de Baleares. A medida que se avanza hacia el sur por las costas mediterráneas españolas, las cornisas de Lithophyllum van siendo reemplazadas por otro tipo de estructuras calcáreas, los denominados "microarrecifes de vermétidos" formados por el gasterópodo Dendropoma petraeum, sedentario y colonial, cuyas conchas forman 
densos agregados que, según crecen, van siendo rellenados y cementados por algas calcáreas incrustantes. La estructura a que dan lugar ambas especies es muy compacta y resistente y adquiere morfologías muy variadas, desde simples recubrimientos, pasando por cornisas y rebordes de distinto desarrollo, hasta complejas formaciones mamelonares en plataformas de abrasión e, incluso, "microatolones", cuando crecen sobre rocas semisumergidas y alcanzan el nivel de la superficie. Estos microarrecifes son endémicos del Mediterráneo y únicamente se desarrollan en sus áreas más cálidas. En nuestras costas sólo aparecen bien desarrollados en el litoral de Alicante, Murcia y Almería, donde existen excelentes ejemplos de todas las morfologías antes descritas. Dendropoma petraeum es uno de los pocos invertebrados marinos incluidos en el Catálogo Nacional de Especies Amenazadas. Por otro lado este tipo de formaciones orgánicas del Mediterráneo están recogidas para su protección por diversos convenios internacionales.

- Los fondos de rodolitos (maërl). En algunas zonas de la plataforma continental se produce una gran acumulación de algas coralinas sueltas, de forma y tamaño variable, que dan lugar a lo que se conoce como fondos de rodolitos o "maërl”, nombre de origen gaélico. A cada una de las algas individuales o elementos que constituyen estos fondos se denomina "rodolito", cuya forma puede variar desde muy ramificada a más o menos esferoidal, dependiendo de las condiciones hidrodinámicas, y su tamaño oscila aproximadamente entre 1 y 6-7 cm. Este tipo de fondos está presente en todos los mares y latitudes del planeta, variando las especies que los componen en función del área geográfica de que se trate. Su distribución batimétrica depende directamente de la transparencia del agua y suelen hallarse en zonas de corrientes intensas. En el Mediterráneo se encuentran a profundidades comprendidas entre 30 y $150 \mathrm{~m}$. En el Atlántico, sin embargo, pueden hallarse a partir de fondos infralitorales poco profundos. Estas algas calcáreas libres añaden complejidad a los homogéneos fondos sedimentarios sobre los que se acumulan, constituyendo un hábitat muy peculiar, con características intermedias entre los sustratos sueltos y los duros. Entre otros, pueden instalarse diversas algas de talo blando, preferentemente rodofíceas, y muchos animales sésiles, sobre todo pequeñas esponjas incrustantes. Todo ello contribuye a crear un microcosmos con una alta diversidad de especies. Los fondos de rodolitos son bien conocidos por los pescadores, que los denominan fondos de "grapissar" en Cataluña y Comunidad Valenciana, o "avellanó” en las Baleares. Estos fondos están muy extendidos a lo largo de todo nuestro litoral, ocupando grandes extensiones, sobre todo en el archipiélago Balear, islas Columbretes e isla de Alborán.

\section{Los fondos coralígenos}

Sin duda, la más compleja e importante de las bioconstrucciones mediterráneas son los Ilamados "fondos coralígenos", los cuales deben su nombre a la abundancia 
de algas coralinas incrustantes. Al contrario que las otras bioconstrucciones mencionadas, que son de aguas superficiales, el coralígeno es característico de mayor profundidad (se encuentra por debajo de 20-25 m), en condiciones de iluminación atenuada y temperatura relativamente uniforme y baja a lo largo de todo el año. Se trata de formaciones organógenas muy complejas, formadas por diversas especies de algas rojas incrustantes de los géneros Mesophyllum, Lithophyllum y Spongites, y muy diversos animales sésiles filtradores, sobre todo cnidarios, briozoos, esponjas y poliquetos serpúlidos, muchos de los cuales presentan llamativos esqueletos calcáreos. Estas formaciones pueden alcanzar varios metros de espesor y están sometidas a un equilibrio dinámico entre la actividad generadora de las especies constructoras y la destrucción causada por diversos organismos perforadores, mayoritariamente esponjas, como las del género Cliona y afines, y algunos bivalvos (de las familias Petricolidae, Hiatellidae o Pholadidae). La acción destructora de estas especies sobre la comunidad coralígena es la que genera los denominados fondos detríticos costeros, los cuales están formados, precisamente, por todo tipo de restos calcáreos fragmentados, mezclados con una proporción variable de sedimentos.

En el coralígeno las algas calcáreas desempeñan fundamentalmente un papel estructural, recubriendo el sustrato y siendo a su vez soporte para muchas especies de animales que viven fijos ellas y que se alimentan filtrando el agua. Toda esta maraña de organismos constituye un complejo hábitat con multitud de nichos, en el que viven numerosísimas especies. Junto a las praderas de Posidonia, los fondos coralígenos constituyen el otro polo de diversidad del Mediterráneo. La fisonomía del paisaje submarino en este tipo de fondos está dominada por los animales sésiles, que además suelen estar vivamente coloreados y pueden alcanzar grandes tallas. Podríamos hablar, en este caso, de auténticos paisajes animales, al contrario de lo que sucede en la mayoría de los paisajes de aguas superficiales, dominados fisonómicamente por la especies vegetales (algas y fanerógamas). Por todo ello, los fondos coralígenos, aparte de su gran interés biológico, presentan un notable valor estético de gran vistosidad y colorido, por lo que son muy apreciados por los buceadores, lo que les confiere un valor económico añadido, debido al extraordinario florecimiento que este sector de la industria turística española ha experimentado en los últimos años.

En el litoral mediterráneo español, los fondos coralígenos mejor conocidos y más visitados por los buceadores son los que se encuentran en las islas Medas, en la Costa Brava, pero se hallan también muy repartidos por buena parte de nuestras costas, aunque siempre ocupando enclaves relativamente reducidos.

Quizás, entre todas las especies que pueblan los fondos coralígenos mediteráneos, las más llamativas y emblemáticas sean las gorgonias (cnidarios octocoralarios), conocidas vulgarmente como "abanicos de mar". Las gorgonias son especies coloniales perennes, cuyas colonias están muy ramificadas y pueden alcanzar 184 años. gran tamaño. Presentan un crecimiento muy lento y una longevidad de decenas de 


\section{Fondos de corales blancos profundos}

En determinadas áreas de los fondos duros batiales, normalmente en zonas escarpadas del talud entre unos 400 y más de $1000 \mathrm{~m}$ de profundidad, pueden existir auténticos "arrecifes de coral” profundos; en este caso corales ahermatípicos (sin zooxantelas) blancos. Las especies dominantes son los madreporarios Lophelia pertusa y Madrepora oculata, que suelen formar agrupaciones mixtas, las cuales pueden llegar a alcanzar más de un metro de altura sobre el sustrato. Estos arrecifes de profundidad albergan una comunidad animal muy diversificada en relación a otras comunidades batiales. Los fondos de corales blancos están muy repartidos geográficamente, pero son especialmente abundantes en el Atlántico norte. En el Mediterráneo se hallan en fase de desaparición y casi siempre aparecen muertos (subfósiles), aunque todavía pueden encontrarse vivos en algunas zonas, como en los alrededores de la isla de Alborán o en los cañones sumergidos situados frente a la Costa Brava. En aguas españolas, los fondos de corales blancos más desarrollados y espectaculares se encuentran en el Banco de Galicia (situado a unas 180 millas al oeste de la costa gallega) a profundidades comprendidas entre unos 500 y 1.000 metros.

\section{BENEFICIOS QUE NOS REPORTA EL MEDIO MARINO}

En primer lugar hay que señalar que el ser humano existe gracias a los mares y océanos, ya que éstos han sido la cuna de todas las formas de vida sobre nuestro planeta. Los servicios de los ecosistemas son los beneficios que las personas obtienen de ellos, destacando entre otros:

- Servicios de aprovisionamiento: alimentos, agua limpia, recursos minerales, sustancias con diversas aplicaciones (farmacología, cosmética), recursos genéticos, etc.

- Servicios de regulación: por ejemplo el clima (los mares intervienen en procesos fundamentales a escala global, como la acumulación y redistribución del calor), las inundaciones, las enfermedades, la calidad del agua.

- Servicios culturales: recreativos y de ocio, estéticos, espirituales, etc.

- Otros servicios de apoyo: los mares y océanos han sido el motor del comercio, la navegación y la exploración geográfica.

La biodiversidad constituye el soporte fundamental para el funcionamiento de los ecosistemas marinos y de los servicios que proporcionan. El funcionamiento de un ecosistema y, por lo tanto, su capacidad para proporcionar servicios al hombre, está determinado en gran medida por las características ecológicas de las especies más abundantes, pero éstas, a su vez, son mantenidas por todo un entramado de especies que, aunque menos abundantes y de un papel más secundario, 
posibilitan el mantenimiento de todo el conjunto y constituyen una parte fundamental de la biodiversidad.

La pérdida local de una especie marina esencial puede alterar los servicios del ecosistema durante mucho tiempo, de la misma forma que los cambios en las interacciones entre especies también pueden tener efectos negativos sobre el conjunto. Aunque la pérdida de biodiversidad puede provocar únicamente efectos menores sobre estos ecosistemas a corto plazo, podría limitar su capacidad para adaptarse en el futuro a entornos cambiantes (como los originados por el cambio climático).

En definitiva la biodiversidad afecta a multitud de procesos de los ecosistemas marinos y, por tanto, a los servicios que prestan. Por ejemplo, una alta diversidad de especies con todo su entramado de relaciones contribuye a mejorar la resistencia de los ecosistemas frente a las especies invasoras. Asimismo, los microorganismos marinos contribuyen a controlar la contaminación al eliminar sustancias tóxicas presentes en el medio, aunque no se conoce del todo cómo influye la diversidad de especies en este proceso de eliminación. También cabe mencionar que la diversidad de determinadas especies bioconstructoras, como las fanerógamas marinas o los corales desempeñan un papel importante en la captura de carbono y, por lo tanto, son relevantes en la lucha contra el cambio climático. Los sustanciales servicios que reportan estas especies bioconstructoras, además, como la generación de hábitats, como zonas de reproducción y cría de peces y otras especies de interés comercial, en el ciclo de nutrientes y en la fijación de carbono y nitrógeno en medios pobres en nutrientes, en la moderación del oleaje o en la estabilización de sedimentos, podrían perderse si se modifican las condiciones que requieren o las interacciones clave entre ellas. El valor económico total de los ecosistemas constituidos por estas especies y los servicios asociados que generan se estima en cientos de millones de dólares.

\section{LAS AGRESIONES AL MEDIO MARINO}

La denominada crisis de la biodiversidad (desaparición o extinción de especies) afecta en menor medida al medio marino que al terrestre, debido principalmente a la mayor capacidad de dispersión de las especies marinas. Pero ello no significa que las agresiones que sufre el mar no se dejen notar, a pesar de que pasan más inadvertidas al público en general. A la vista de todos está la progresiva degradación de nuestras costas y de la calidad de las aguas que las bañan, al tiempo que se agotan los recursos pesqueros. Aunque las agresiones que sufre el mar no se traduzcan en la extinción de especies al mismo ritmo que en el medio terrestre, sí ocasionan importantes deterioros y desequilibrios en las comunidades marinas y a una pérdida generalizada de su biodiversidad.

Aunque las extinciones biológicas (desaparición total de una especie) son raras en el medio marino, si puede hablarse aquí en muchos casos de extinción funcional o 186 ecológica. Ello hace referencia a la rarefacción de las poblaciones de muchas especies 
por debajo de determinados niveles, de manera que pierden la funcionalidad original o importancia que desempeñaban antaño en los ecosistemas.

El progresivo y alarmante conjunto de alteraciones que sufre nuestra costa se traduce en una acusada homogeneización de la misma. Buena parte de nuestro litoral mediterráneo ha sido ocupado por infraestructuras, con una sucesión casi ininterrumpida de espigones, playas artificiales, puertos deportivos, paseos marítimos, urbanizaciones, hoteles y otros servicios asociados. Ello supone una pérdida de los valores singulares de cada zona, un empobrecimiento paisajístico y una pérdida y deterioro generalizados de los hábitats naturales. El reflejo de esta homogeneización y pérdida de naturalidad, se traduce obviamente en una acusada pérdida de diversidad, a lo que se suma el deterioro de la calidad del agua. Es lo que se denomina "banalización del medio". En este proceso, las especies que antes eran raras ahora han desaparecido de algunas zonas, muchas de las especies comunes se han vuelto raras y son casi siempre las mismas especies (especies muy tolerantes y oportunistas) las que tienden a dominar por todos lados. El resultado de este proceso es siempre el mismo: paisajes monótonos (en tierra y bajo el agua), diversidad biológica baja y proliferación de especies banales en detrimento de las más interesantes.

En este sentido, la reciente Directiva marco europea sobre la Estrategia Marina hace especial hincapié en la necesidad de que los países se comprometan a restaurar en la medida de lo posible las condiciones originales de naturalidad del litoral. Ello en España parece difícil debido al alto grado de construcción y deterioro de la costa. Un ejemplo elocuente lo constituyen los múltiples proyectos de ampliación de casi todos los puertos españoles (ya realizados, en ejecución o en proyecto), con el argumento en cada caso de que cada uno se convierta en el más importante de su entorno geográfico.

Por otro lado, las agresiones tradicionales que recibe el medio marino por parte del hombre (contaminación de origen industrial y urbano, aporte de nutrientes, vertidos de hidrocarburos, construcción de infraestructuras costeras, desarrollo urbanístico desmesurado, sobreexplotación de recursos, etc.) se añaden otras más recientes, como la creación de playas artificiales, las "granjas de engorde" de pescado (de doradas, lubinas y atunes, principalmente), las plantas desalinizadoras, los campos eólicos marinos, el desarrollo de la floreciente industria del buceo o de determinadas actividades náuticas (proliferación de motos acuáticas). Estas actuaciones humanas, algunas de las cuales, que de forma aislada pueden resultar beneficiosas y ocasionar escaso impacto si se desarrollan de una forma racional, cuando se generalizan de forma abusiva y actúan todas ellas de forma sinérgica, se suman a todo el conjunto de agresiones y provocan un impacto añadido.

La mala regeneración de algunas playas (en muchos casos se trata de la creación de playas artificiales donde no las había) altera de forma muy notoria la dinámica de los sedimentos litorales y modifica considerablemente la estructura y granulometría de los fondos circundantes a las zonas de extracción de áridos. Ello produce impor- 
tantes daños a las comunidades de los fondos blandos, uno de cuyos factores limitantes es, precisamente, la granulometría del sedimento. Pero esta actividad tiene también importantes repercusiones en los fondos rocosos cercanos, pues se produce con ello la resuspensión de las partículas más finas y un enturbiamiento del agua. Esto afecta de forma directa a las comunidades vegetales, que reciben menos luz, con especial incidencia en las praderas de Posidonia oceanica, y, a su vez, provoca la muerte de diversas especies de animales sésiles filtradores (esponjas, gorgonias, ascidias, etc) por la deposición sobre ellos de sedimentos finos. Sobra decir que los temporales de otoño vuelven a llevarse la arena depositada artificialmente, pues el mar se ocupa de situarla en los lugares que le corresponde en función la las corrientes y dinámica litoral.

Hay que tener en cuenta también que en los últimos 20 años la transparencia de las aguas costeras del Mediterráneo ha disminuido en unos $2 \mathrm{~m}$, debido también a la su creciente eutrofización. Dado que la luz es el factor limitante de la vegetación marina, ello supone que en las últimas dos décadas el límite inferior de los lechos de algas y fanerógamas marinas ha retrocedido dos metros en profundidad. En los fondos aplacerados esto se traduce en la desaparición de la vegetación en extensas áreas.

Asimismo, las granjas de engorde de pescado producen una considerable eutrofización de los fondos sobre los que se instalan, debido a la acumulación de los restos del alimento y a la deposición de heces. Además, se empieza a detectar la proliferación de enfermedades infecciosas derivadas de la alta concentración de peces.

Por otro lado, las plantas desalinizadoras vierten al mar las sales generadas en el proceso de desalación, con lo cual se produce un aumento local de la salinidad. En principio, si se siguen una serie de recomendaciones en la instalación de estas plantas, el efecto de las salmueras que vierten al medio puede mitigarse sin dificultad. Pero, aparte del enorme gasto energético que conllevan, el problema reside en que con ellas se persigue eliminar el factor limitante al proceso urbanizador de la costa mediterránea, que es la escasez de agua. Dado que ya se ha sobrepasado la "capacidad de carga” del sistema costero (sobresaturación del litoral), el agua disponible debiera servir para marcar los límites a este desmesurado e insostenible desarrollo urbanístico.

De otra parte, el buceo de tipo recreativo viene a concentrarse en los lugares de fondos rocosos mejor conservados y más vistosos. Ello produce en determinados lugares de gran interés una excesiva concentración de buceadores en espacios reducidos. Ejemplos elocuentes de ello lo constituyen las Islas Medas o la Reserva Marina de Cabo de Palos e islas Hormigas. Aún reconociendo el creciente esfuerzo de los clubes de buceo por el respeto al medio, es inevitable el efecto erosivo de los buceadores sobre determinadas comunidades de animales filtradores bentónicas de sustratos duros, muy frágiles y que son muy frecuentadas (por ejemplo, los fondos cora188 lígenos con grandes briozoos). 
Otra actividad que debe tenerse en cuenta de cara a la conservación de la diversidad litoral es el marisqueo indiscriminado, entendiendo como tal cualquier extracción de organismos marinos en las costas. Mientras dicha actividad está totalmente regulada en la comunidad autónoma gallega o en Baleares, donde se prohíbe la extracción de cualquier especie marina si no es con autorización expresa, en otras su regulación deja mucho que desear, con algunas excepciones como la recolección de algas del género Gelidium y de erizos (Paracentrotus lividus) en Asturias. Es muy frecuente ver a familias enteras deambulando por los roquedos costeros, armadas con todo tipo de artilugios de captura (pinchos, tridentes, salabres, cañas de pescar, fusiles subacuáticos), dedicadas a la recolección de lapas, erizos, pulpos, cangrejos, etc. En algunas zonas la actividad marisquera se centra en determinadas especies con una finalidad comercial. Un ejemplo alarmante es, por ejemplo, la recolección de lapas en Canarias, las cuales constituyen un plato típico en el archipiélago y alcanzan un alto precio en el mercado. Esta actividad está causando importantes estragos en las poblaciones de las especies endémicas del archipiélago (Patella candei, $P$. crenata y $P$. piperata, la primera de ellas en peligro de extinción). Otro ejemplo muy reciente de actividad marisquera es la recogida de anémonas (Anemonia sulcata) para su consumo en el litoral de Málaga y de Cádiz. Dicha extracción, que antes era muy puntual, ha proliferado mucho en los últimos años, para la cual suelen voltearse las rocas situadas en fondos poco profundos. Este volteo masivo produce importantes daños en las comunidades biológicas que viven en los "pedreros", con especial incidencia en la denominada "comunidad infralapidícola" (la que vive debajo de las rocas). Otro caso muy especial de marisqueo lo constituye la recolección del dátil de mar (Lithophaga lithophaga), especie incluida en la Directiva Hábitats y en el Anexo II del Convenio de Barcelona y, por tanto, cuya captura y comercio es totalmente ilegal. Para la recogida de esta especie es preciso romper las rocas en el interior de las cuales vive, por lo que su captura ocasiona importantes destrozos. Esta especie se sigue recogiendo para su venta a restaurantes sobre todo en las costas de Castellón e islas Baleares, donde existe una gran tradición en su consumo.

En definitiva, la pérdida de muchos de los roquedos litorales por un lado y el marisqueo indiscriminado en los que quedan ha conducido a un alarmante deterioro y empobrecimiento biológico de la mayor parte de ellos.

Asimismo, y dejando de lado los impactos directos ocasionados por las actividades humanas antes mencionadas y la dramática reducción de las poblaciones de muchas de las especies sometidas a explotación, son muchos los ejemplos que nos muestran la situación de estrés a la que se encuentran sometidas nuestras aguas costeras. Cabe citar las plagas cada vez más frecuentes de determinadas especies, como medusas, o de las denominadas por los pescadores "babas", "lipón” o "llepó” (mucosidades producidas por proliferaciones anormales de determinadas diatomeas). Por otro lado, se vienen detectando frecuentes mortandades masivas de algunas especies en determinadas zonas, como las de los erizos comunes, que tienen lugar algunos veranos (la última en el verano de 2001 en el levante español), la del bivalvo Spondylus gaederopus ("ostra roja”) ocurrida en todo el Mediterráneo a principios de 
la década de los ochenta, o la que afectó a diversas especies de gorgonias, esponjas y ascidias en toda la ribera del Mediterráneo noroccidental en el verano de 1999 (en las costas españolas sólo incidió de forma aparente al litoral norte de Menorca). Todos estos eventos probablemente se deban a una combinación de factores (exceso de nutrientes, temperaturas anormalmente altas, enfermedades de diverso origen y otros todavía por determinar), y sean también reflejo de los grandes desequilibrios existentes, con la drástica reducción de las poblaciones de algunas especies y la proliferación de otras. Un ejemplo de lo anterior lo constituye la proliferación excesiva del "erizo de lima" (Diadema antillarum) en los fondos canarios, que ha traído consigo la desaparición casi total de algas erectas en amplias superficies, que resultan muy empobrecidas y reciben el nombre de "blanquizales". Muchos de estos eventos son conocidos desde antiguo en el Mediterráneo y parecen presentar un carácter cíclico con una periodicidad más o menos decadal, pero en los últimos años aparecen de forma casi continuada.

A todos estos problemas hay que sumar los efectos del cambio global (aumento de la temperatura del mar, de la acidificación, ... ) y la creciente introducción de especies foráneas. Muchas de las especies introducidas por la acción humana no llegan a causar daños en los ecosistemas receptores, pero en algunos casos pueden tener carácter invasor y ocasionar verdaderas plagas, desplazando a las especies autóctonas y produciendo importantes alteraciones en las comunidades originales. Quizás los ejemplos más elocuentes los encontremos entre las algas. En el Mediterráneo el alga clorofícea tropical Caulerpa racemosa es la más extendida, pero otra serie de ellas están desplazando a las especies autóctonas. Ello viene siendo especialmente preocupante en las islas Baleares. En lo que se refiere a las costas atlánticas europeas, otra alga (Sargassum muticum), oriunda de Japón, ha alcanzado también carácter de plaga, afectando a las costas del norte de España.

\section{MEDIDAS INTERNACIONALES DE CONSERVACIÓN DE LA BIODIVERSIDAD MARINA}

Para lograr una adecuada conservación y uso racional de los recursos marinos y costeros, los países han firmado y ratificado numerosos convenios y acuerdos internacionales. Los más destacados son los siguientes:

- Convenio de Naciones Unidas sobre derecho del mar (UNCLOS, 1982).

- Convenios de mares regionales

- Convenio de Barcelona $(1976,1995)$ para la protección del medio marino y de la región costera del Mediterráneo:

- Protocolo sobre las Zonas Especialmente Protegidas y la Diversidad Biológica en el Mediterráneo (1995) 
- Convenio de París (OSPAR, 1992) para la protección del medio ambiente marino del Atlántico Nordeste:

- Anexo V sobre la protección y conservación de los ecosistemas y de la diversidad biológica de las áreas marítimas (1998)

- Convenio de Bonn (1979) sobre la conservación de las especies migratorias de fauna silvestre:

- Acuerdo de Mónaco sobre la conservación de cetáceos del Mar Negro, Mar Mediterráneo y Zona Atlántica Contigua (ACCOBAMS, 1996).

- Acuerdo de Canberra para la conservación de albatros y petreles (ACAP, 2002).

- Convenio de Río de Janeiro (1992) sobre la Diversidad Biológica:

- Mandato de Yakarta sobre biodiversidad marina y costera (1995).

- Directivas comunitarias europeas:

- Directiva 2008/56/CE marco de acción comunitaria para la política del medio marino (Directiva sobre la Estrategia Marina)

- Directiva 92/43/CEE (1992) del Consejo sobre conservación de los hábitat naturales y la fauna y flora silvestres

- Directiva 79/409/CEE (1979) del Consejo relativa a la conservación de aves silvestres

En la actualidad la conservación, tanto en el medio terrestre como en el marino, se centra preferentemente en las especies consideradas amenazadas y en los espacios protegidos. Sin quitar importancia a lo anterior, se plantea una vez más la disyuntiva de si es mejor centrar los esfuerzos de conservación en aquellas especies en situación alarmante, o si sería mejor hacer mayor esfuerzo en que el resto de las especies no alcancen la nada deseable "distinción" de amenazadas. Posiblemente, lo más adecuado, como casi siempre, sea un equilibrio entre ambas situaciones. En lo que se refiere a las áreas marinas protegidas, se ha demostrado su papel en la recuperación de muchas especies sometidas a presión humana, sobre todo las especies de peces objeto de pesca submarina o los grandes crustáceos. Está claro que estas áreas protegidas actúan como exportadoras de larvas a otras zonas, pero no tanto como receptoras, por el deterioro del medio fuera de ellas. Por tanto, el balance de los efectivos poblacionales dentro de la reserva puede ser deficitario (se exportan pero no se importan), por lo que a la larga puede producirse también una pérdida de biodiversidad dentro de ellas. Debe tenerse en cuenta, como ya se ha comentado, que el mar no conoce fronteras ni demarcaciones, por lo que de nada sirve proteger adecuadamente determinadas especies o sectores de costa, si las aguas que los ba- 
ñan no reúnen la calidad suficiente y si el entorno donde están enclavados sigue deteriorándose al ritmo actual.

No obstante, las medidas que ya se están adoptando a nivel internacional y nacional nos hacen abrigar ciertas esperanzas de cara a mejorar la protección de nuestros mares.

TABLA 2

Número de especies de los distintos grupos vegetales y animales pluricelulares a nivel mundial, europeo, mediterráneo, español (incluyendo Canarias) y canario

\begin{tabular}{|c|c|c|c|c|c|c|}
\hline & & Mundiales & Europeas & Mediterráneas & Españolas & Canarias \\
\hline & ALGAS & 6.600 & 1684 & 980 & 1035 & 639 \\
\hline & Clorofitas & 1.100 & 328 & 200 & 215 & 118 \\
\hline & Feofitas & 1.500 & 437 & 260 & 270 & 130 \\
\hline & Rodofitas & 4.000 & 919 & 520 & 550 & 391 \\
\hline & ANGIOSPERMAS & 55 & 5 & 5 & 5 & 3 \\
\hline & ANIMALES & 188.349 & 24.185 & 12.000 & 9.253 & 3.950 \\
\hline & Poríferos & 9.000 & 1.640 & 590 & 550 & 157 \\
\hline & * Placozoos & 2 & 2 & 2 & 1 & - \\
\hline & * Mesozoos & 85 & 35 & 20 & $?$ & - \\
\hline & Cnidarios & 10.000 & 1.329 & 730 & 650 & 164 \\
\hline & * Ctenóforos & 110 & 38 & 30 & 30 & 4 \\
\hline & Platelmintos & 15.000 & $2.398(?)$ & 900 & $?$ & 37 \\
\hline & Rotíferos & 250 & 139 & 59 & 20 & - \\
\hline & * Gnatostomúlidos & 80 & 25 & 10 & 4 & - \\
\hline \multirow{11}{*}{ 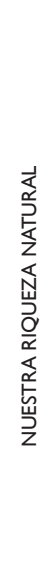 } & Nemertinos & 750 & 478 & 187 & 45 & - \\
\hline & * Gastrotricos & 400 & 237 & 165 & $?$ & - \\
\hline & * Loricíferos & 10 & 2 & 2 & 1 & - \\
\hline & * Kinorrincos & 120 & 37 & 28 & 5 & 1 \\
\hline & Ciclióforos & 4 & 3 & 2 & 3 & - \\
\hline & Nematomorfos & 10 & 3 & 1 & $?$ & - \\
\hline & * Priapúlidos & 15 & 7 & 5 & 3 & - \\
\hline & Nematodos & 12.000 & 1837 & 703 & $?$ & - \\
\hline & Acantocéfalos & 200 & 67 & $?$ & $?$ & - \\
\hline & * Entoproctos & 170 & 45 & 19 & 5 & - \\
\hline & * Equiúridos & 140 & 19 & 6 & 5 & 2 \\
\hline & * Sipuncúlidos & 160 & 44 & 33 & 35 & 6 \\
\hline
\end{tabular}


TABLA 2 (cont.)

Número de especies de los distintos grupos vegetales y animales pluricelulares a nivel mundial, europeo, mediterráneo, español (incluyendo Canarias) y canario

\begin{tabular}{|c|c|c|c|c|c|}
\hline & Mundiales & Europeas & Mediterráneas & Españolas & Canarias \\
\hline Moluscos & 60.000 & 3.353 & 2.800 & 2.250 & 1.170 \\
\hline Anélidos & 12.000 & 2.074 & 1.100 & 1.000 & 305 \\
\hline * Pogonóforos & 120 & 23 & 5 & 3 & - \\
\hline Tardígrados & 120 & 76 & 60 & 20 & - \\
\hline Quelicerados & 1.000 & 361 & 275 & 190 & 12 \\
\hline Crustáceos & 38.000 & $6.522(?)$ & 2.600 & 2.500 & 1.095 \\
\hline Briozoos & 4.000 & 724 & 250 & 280 & 131 \\
\hline * Braquiópodos & 350 & $18(?)$ & 16 & 31 & 15 \\
\hline * Foronídeos & 16 & 9 & 8 & 8 & 2 \\
\hline * Quetognatos & 70 & 42 & 25 & 30 & 22 \\
\hline * Hemicordados & 90 & 17 & 5 & 5 & - \\
\hline * Equinodermos & 7.000 & 648 & 230 & 275 & 82 \\
\hline Cordados & 17.123 & 1.933 & 921 & 1.532 & 745 \\
\hline (* Urocordados) & 2.100 & 481 & 320 & 350 & 28 \\
\hline (* Cefalocordados) & 23 & 2 & 1 & 2 & - \\
\hline (Vertebrados) & 15.000 & 1.450 & 900 & 1.180 & 717 \\
\hline Totales & $\cong 195.000$ & 25.871 & $\cong 13.000$ & $\cong 10.300$ & 4.592 \\
\hline
\end{tabular}

Se han señalado con un asterisco los grupos exclusivamente marinos. Los números de especies mundiales, mediterráneas y españolas son estimativos o aproximados y se refieren a especies descritas y citadas (no a especies posibles). En muchos casos el número de especies citadas es muy inferior al real, debido a un deficiente conocimiento del grupo en ese área geográfica. Las interrogaciones en la columna de las especies españolas se refieren a aquellos grupos cuyo número de especies citadas se considera inferior al $5 \%$ de las que deben existir. Por otro lado, los números que se consignan en las columnas de especies europeas y canarias no son estimativos, sino que corresponden con exactitud a los que figuran en el European Register of Marine Especies (Costello et al., 2001) y a las recogidas en el "Proyecto BIOTA" (Moro et al., 2003), respectivamente. En lo que se refiere a la lista de especies europeas, los números referentes a los platelmintos y a los crustáceos están sobredimensionados, posiblemente por haberse incluido también las especies no marinas (esto claramente sucede con los isópodos, dentro de los crustáceos, y con los grupos parásitos, dentro de los platelmintos). Por el contrario, la cifra de braquiópodos parece subestimada, pues el número de especies citadas de este grupo en los mares europeos debe ser próximo a 40. De cara a llamar la atención sobre ello, se ha puesto una interrogación a continuación de las cifras dadas para estos grupos. 
